\title{
The Effect of Natural Silica from Rice Husk Ash and Nickel as a Catalyst on the Hydrogen Storage Properties of $\mathrm{MgH}_{2}$
}

\author{
Malahayati ${ }^{1,2}$, Evi Yufita ${ }^{2}$, Ismail Ismail ${ }^{2}$, Mursal Mursal ${ }^{2}$, \\ Rinaldi Idroes ${ }^{3}$, Zulkarnain Jalili2,* \\ 1 Graduate School of Mathematics and Applied Sciences, Universitas Syiah Kuala, Banda Aceh 23111, \\ Indonesia \\ 2 Department of Physics, Faculty of Mathematics and Natural Sciences, Universitas Syiah Kuala, \\ Banda Aceh 23111, Indonesia \\ 3 Department of Chemistry, Faculty of Mathematics and Natural Sciences, Universitas Syiah Kuala, \\ Banda Aceh 23111, Indonesia \\ * Corresponding author's e-mail: zjalil@unsyiah.ac.id
}

\begin{abstract}
The characteristics of $\mathrm{MgH}_{2}$ as a hydrogen storage material in this study were observed by varying the composition of the catalyst. The added catalyst was a dual catalyst, namely nickel and natural silica extracted from rice husk ash with a composition of $\mathrm{MgH}_{2}+10 \mathrm{wt} \% \mathrm{SiO}_{2}+10 \mathrm{wt} \% \mathrm{Ni}$ (Sample A), then $\mathrm{MgH}_{2}+5 \mathrm{wt} \% \mathrm{SiO}_{2}+10 \mathrm{wt} \% \mathrm{Ni}$ (Sample B), and $\mathrm{MgH}_{2}+10 \mathrm{wt} \% \mathrm{SiO}_{2}+5 \mathrm{wt} \% \mathrm{Ni}$ (sample C). The samples were prepared using the high energy ball milling (HEBM). The results showed that the natural silica extracted from rice husk ash (hereafter called "RHA") can be used as a catalyst in $\mathrm{MgH}_{2}$. Then, simultaneous use of nickel with silica as dual catalyst has shown the improvement in the hydrogen storage characteristics such as temperature and desorption time. The results of this study also indicate that the composition of the catalyst affects the particle size, although the time and milling treatment are the same. Furthermore, the particle size affects the characteristics of $\mathrm{MgH}_{2}$ as a hydrogen storage material. Apart from particle size, there are other parameters that influence the characteristics of $\mathrm{MgH}_{2}$, which appear during the sample preparation process such as impurity and agglomeration phases, all of which are closely related to the composition and type of catalyst used and the milling treatment applied to the sample. The 10 hours milling time used in this study has succeeded in reducing the sample to nano size. The Mg-based materials which have a nanostructure will have a larger contact area for the hydrogen reaction. The diffusion distance during the hydrogen absorption reaction also becomes smaller so as to improve the kinetic and thermodynamic characteristics of $\mathrm{MgH}_{2}$.
\end{abstract}

Keywords: hydrogen storage, natural silica, rice husk ash, high energy ball milling, desorption temperature

\section{INTRODUCTION}

Hydrogen is an important source of energy, and a candidate for replacing fossil fuels, because hydrogen has the potential to be a clean, reliable and affordable energy source. The main advantage of this fuel is that the combustion product is in the form of water so that it does not pollute the environment unlike the $\mathrm{CO}$ and $\mathrm{CO}_{2}$ produced from fossil fuels.

Hydrogen can be stored in a solid storage form by inserting it between the atoms of other compounds. Hydrogen atoms penetrate into the inner layer of the metal, then spread out and finally occupy a certain position on the metal lattice. The hydrogen which is embedded in the metal will form a solid solution. The temperature at which hydrogen atoms insert into the metal is called the adsorption temperature. Meanwhile, the temperature at which the $\mathrm{H}$ atoms recombine to form hydrogen molecules is known as the desorption temperature.

Certain metals begin absorbing hydrogen in a solid solution state or also called $\alpha$-phase, a state 
where hydrogen atoms begin to insert into the metal. When the pressure and hydrogen concentration are increased, the position of the hydrogen atoms is more properly arranged in the metal lattice (localized) and nucleation appears accompanied by the formation of hydrides. This state is referred to as $\beta$-phase (Varin et al., 2006).

In non-metallic materials, hydrogen is stored in porous materials such as carbon in the form of nanotubes. Even though the operating temperature is low, the hydrogen storage capacity of this material is relative small (Sudibandriyo et al., 2015). Nasruddin et al. (2016) found the optimum adsorption capacity of open-ended single-walled carbon nanotubes equal to $1.75 \mathrm{wt} \%$ at a temperature of $233 \mathrm{~K}$ and a pressure of $10 \mathrm{MPa}$. Numerous metallic types are believed to be capable of absorbing large amounts of hydrogen and have the potential to store hydrogen. $\mathrm{MgH}_{2}$ is a metal that has prospects as a storage material for hydrogen because it is able to absorb large amounts of hydrogen, which is $7.6 \mathrm{wt} \%$. This value is higher than the determined limit agreed by the world energy agency of $5 \mathrm{wt} \%$. Besides that, the nature of $\mathrm{Mg}$ which is light, easy to obtain and the price is affordable is also another consideration for world researchers currently investigating $\mathrm{MgH}_{2}$ as a hydrogen storage material. However, the $\mathrm{MgH}_{2}$ material has several disadvantages to be widely applied as a hydrogen storage material, namely its high operating temperature $\left(>350^{\circ} \mathrm{C}\right)$ and its slow chemical reaction.

Several studies have shown that adding a catalyst and refining the particle size to the nanometres scale can improve the hydrogen storage properties of the $\mathrm{MgH}_{2}$ material (Hong \& Song, 2018; Hou et al., 2013; Khodaparast \& Rajabi, 2015; Li et al., 2018; Malahayati, Nurmalita, et al., 2021; Malahayati, Yufita, et al., 2021; Yartys et al., 2019). Kinetic improvement still exists when the particle size of $\mathrm{MgH}_{2}$ is below $50 \mathrm{~nm}$ (Kou et al., 2013). Jalil et al. (2016) informed that by $1 \mathrm{wt} \%$, $3 \mathrm{wt} \%$ and $5 \mathrm{wt} \%$ nano-silica $\left(\mathrm{SiO}_{2}\right)$, extracted from local RHA and similar to the silica from local beach sand (Jalil et al., 2018), the thermodynamics and kinetics of magnesium hydrides can develop. In addition, it has been described that a small quantity of metal catalysts, in particular $\mathrm{Ni}$, can increase the hydrogen characteristic of magnesium hydrides in nanometer scale (Berlouis et al., 2001; Jalil et al., 2017; Jalil et al., 2018; Khan et al., 2018; Kwak et al., 2015; Mustanir \& Jalil, 2009; Rahwanto et al., 2021; Ranjbar et al., 2009;
Zeng et al., 2020; Zhang et al., 2017; Zhang et al., 2017). The positive effect of improving certain characteristics of the hydrogen storage material can be attended by a reduction in other characteristics, relevant to the hydrogen storage material (Yartys et al., 2019). Therefore, research is currently focused on the exploration of additional efficient elements, especially multi-functional materials, namely materials that can simultaneously improve the thermodynamics and kinetics of $\mathrm{MgH}_{2}$.

The research related to the use of multi-functional material (double catalysts) in hydrogen storage materials has been carried out by numerous researchers (Chen et al., 2019; Rahwanto et al., 2020; Rajabpour et al., 2016; Ranjbar et al., 2009). However, the use of Ni catalysts and natural silica with the composition as in this paper has not been reported thus far. The use of double catalysts with the suitable composition is expected to improve the kinetic and thermodynamic characteristics of the $\mathrm{MgH}_{2}$ material.

In this work, pure nickel $(\mathrm{Ni})$ and natural silica $\left(\mathrm{SiO}_{2}\right)$ which was extracted from RHA, have been used as a catalyst in $\mathrm{MgH}_{2}$. The composition of catalysts used in this study was varied as follows: $\mathrm{MgH}_{2}+10 \mathrm{wt} \% \mathrm{SiO}_{2}+10 \mathrm{wt} \% \mathrm{Ni}$ (Sample A); then $\mathrm{MgH}_{2}+5 \mathrm{wt} \% \mathrm{SiO}_{2}+10 \mathrm{wt} \% \mathrm{Ni}(\mathrm{Sam}-$ ple B); and $\mathrm{MgH}_{2}+10 \mathrm{wt} \% \mathrm{SiO}_{2}+5 \mathrm{wt} \% \mathrm{Ni}$ (sample C). Sample preparation was carried out using a planetary ball milling equipment through a milling time of 10 hours.

\section{MATERIALS AND METHOD}

Pure $\mathrm{MgH}_{2}(99.99 \%$, size $50 \mu \mathrm{m})$ and $\mathrm{Ni}$ $(99.99 \%$, size $90 \mathrm{~nm})$ powder were used in this study. Natural silica was obtained from the extraction of RHA using co-precipitation method, as published elsewhere (Malahayati et al., 2018). The samples were milled for 10 hours with the following composition: (A) $\mathrm{MgH}_{2}+10 \mathrm{wt} \% \mathrm{SiO}_{2}$ $+10 \mathrm{wt} \% \mathrm{Ni}$ ); (B) $\mathrm{MgH}_{2}+5 \mathrm{wt} \% \mathrm{SiO}_{2}+10 \mathrm{wt} \%$ $\mathrm{Ni}$; (C) $\mathrm{MgH}_{2}+10 \mathrm{wt} \% \mathrm{SiO}_{2}+5 \mathrm{wt} \% \mathrm{Ni}$. The samples were then mixed and milled using a planetary ball mill (Fritsch, P6) through a ball to powder ratio (BPR) of 10:1 and a speed of $350 \mathrm{rpm}$. The composition phase of the samples was obtained by using x-ray diffraction (XRD; Shimadzu D6000, $\mathrm{Cu}-\mathrm{K} \alpha$ radiation $\lambda=1.54060 \mathrm{~A}$ ). Morphological structures and thermal properties were detected by scanning electron microscopy 
(SEM; Philips, XL30) Thermogravimetic Analyzer (TGA) and Differential Scanning Calorimetric (DSC; Shimadzu, D50).

\section{RESULTS AND DISCUSSION}

Figure 1 shows the XRD pattern of $\mathrm{MgH}_{2}+$ $10 \mathrm{wt} \% \mathrm{SiO}_{2}+10 \mathrm{wt} \% \mathrm{Ni}, \mathrm{MgH}_{2}+5 \mathrm{wt} \% \mathrm{SiO}_{2}$ $+10 \mathrm{wt} \% \mathrm{Ni}$ and $\mathrm{MgH}_{2}+10 \mathrm{wt} \% \mathrm{SiO}_{2}+5 \mathrm{wt} \%$ Ni. It was shown that the impurity phase appears in sample A. This sample also has a narrow peak width. Meanwhile, samples $B$ and $C$ have a wide peak width. This means that sample $\mathrm{A}$ has a larger crystallites size than sample B and C. The crystallites size were calculated by the Scherer method (Patternson, 1939) and the summary results can be seen in Table 1 .

The crystallites size affects the thermal properties of the sample as shown in the DSC (Figure 2) and TGA (Figure 3) curves. The reduction in crystallites size causes a decrease in the desorption temperature. The desorption temperatures of samples A, B, and C were $356.37^{\circ} \mathrm{C}$, $286.66^{\circ} \mathrm{C}$ and $288.23^{\circ} \mathrm{C}$, respectively.

Furthermore, the results of the thermal analysis carried out through DSC and TGA are presented in Figures 2 and 3. The DSC curve shows that the variations in the composition of the catalyst have an effect on the desorption temperature. Meanwhile, the TGA curve shows the influence of catalyst composition on desorption time and mass loss. Thermal investigation through DSC and TGA provides the data as shown in Table 2.
Microstructure observations are shown in Figure 4, 5 and 6. Sample A (Fig. 4) with a composition of $\mathrm{MgH}_{2}+10 \mathrm{wt} \% \mathrm{SiO}_{2}+10 \mathrm{wt} \% \mathrm{Ni}$, appears to have the largest particle size, followed by sample B (Fig. 5) with a composition of $\mathrm{MgH}_{2}$ $+5 \mathrm{wt} \% \mathrm{SiO}_{2}+10 \mathrm{wt} \% \mathrm{Ni}$, and sample C (Fig. 6) with a composition of $\mathrm{MgH} 2+10 \mathrm{wt} \% \mathrm{SiO} 2+5$ $\mathrm{wt} \% \mathrm{Ni}$. This data is consistent with the results shown by XRD.

The phase, thermal and microstructure investigations in this study have consistently shown the effect of the catalyst composition on the characteristics of the hydrogen storage material $\mathrm{MgH}_{2}$. Sample A $\left(\mathrm{MgH}_{2}+10 \mathrm{wt} \% \mathrm{SiO}_{2}+10 \mathrm{wt} \% \mathrm{Ni}\right)$ have a high desorption temperature, but it only takes 6.67 minutes to release $11 \%$ of the mass of hydrogen. This means that the kinetic characteristics of the sample A were successfully improved, even though the improvement in their thermodynamic characteristics was not significant. The impurity layer that appears in sample A adheres to the particle surface which is also the grain boundary plane. These impurities can block the penetration and diffusion pathways of hydrogen into the bulk, destroying the intersection between the grain boundary plane and the particle surface, which is the penetration and diffusion pathway of hydrogen into the bulk (Varin et al., 2009). The appearance of impurity is caused by the nature of $\mathrm{MgH}_{2}$ which is easily oxidized through oxygen and air (Sadhasivam et al., 2017)

The sample with a higher weight percent $\mathrm{Ni}$ $\left(\mathrm{MgH}_{2}+5 \mathrm{wt} \% \mathrm{SiO}_{2}+10 \mathrm{wt} \% \mathrm{Ni}\right)$ or sample B showed the lowest desorption temperature among

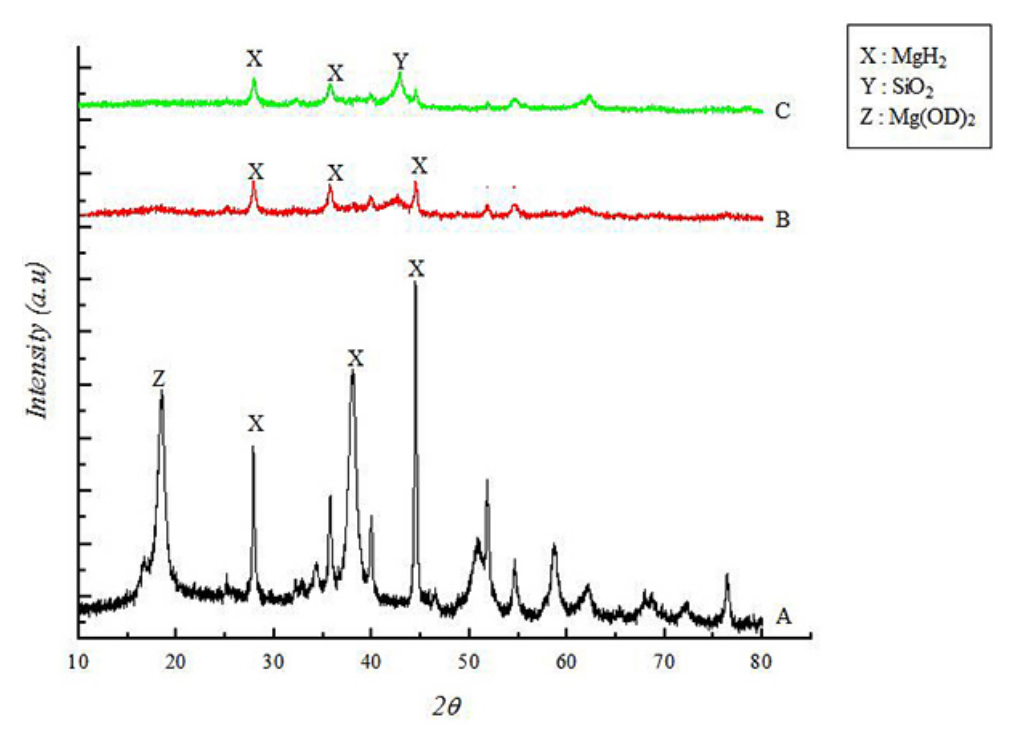

Figure 1. $\mathrm{XRD}$ pattern of $\mathrm{MgH}_{2}+10 \mathrm{wt} \% \mathrm{SiO}_{2}+10 \mathrm{wt} \% \mathrm{Ni}(\mathrm{A}), \mathrm{MgH}_{2}+5 \mathrm{wt} \%$ $\mathrm{SiO}_{2}+10 \mathrm{wt} \% \mathrm{Ni}(\mathrm{B})$ and $\mathrm{MgH}_{2}+10 \mathrm{wt} \% \mathrm{SiO}_{2}+5 \mathrm{wt} \% \mathrm{Ni}(\mathrm{C})$. 
Table 1. The result of calculating the crystal size

\begin{tabular}{|l|c|c|c|}
\hline Sample code & $2 \theta$ & FWHM & Crystal size \\
\hline A (composition 1) & 44.4436 & 0.25940 & 34.92 \\
\hline B (composition 2) & 27.8798 & 0.48470 & 17.83 \\
\hline C (composition 3) & 42.732 & 1.06400 & 8.46 \\
\hline
\end{tabular}

Table 2. The TGA and DSC results for different composition.

\begin{tabular}{|c|c|c|c|}
\hline Sample & $\begin{array}{c}\text { Desorption } \\
\text { temperature }\left({ }^{\circ} \mathrm{C}\right)\end{array}$ & $\begin{array}{c}\text { Desorption } \\
\text { time }(\mathrm{min})\end{array}$ & $\begin{array}{c}\text { Lost mass of } \\
\text { hydrogen }(\%)\end{array}$ \\
\hline $\mathrm{A}$ & 356.37 & 6.67 & 11 \\
\hline $\mathrm{B}$ & 286.66 & 11.37 & 6.4 \\
\hline $\mathrm{C}$ & 288.23 & 8.3 & 5.7 \\
\hline
\end{tabular}

the three samples. However, it took 11.37 minutes to remove $6.4 \%$ hydrogen. Sample $\mathrm{C}\left(\mathrm{MgH}_{2}+10\right.$ $\mathrm{wt} \% \mathrm{SiO}_{2}+5 \mathrm{wt} \% \mathrm{Ni}$ ) has the smallest particle size among the three samples. This is due to the high percentage of silica in this sample. Silica as a catalyst has a hardening effect that will accelerate the process of breaking $\mathrm{MgH}_{2}$ powder (Jalil, Rahwanto, Sofyan, et al., 2018). The small particle size will increase the kinetic of hydrogen absorption and desorption (Li et al., 2018). The desorption temperature of this sample is also relatively low, and it took 8.3 minutes to release $5.7 \%$ mass of hydrogen. The optimum condition was achieved by sample $C$, because in this sample, the thermodynamic and kinetic were significantly improved compared to other samples.

The results of this study indicate that the natural silica catalyst combined with pure nickel in the right composition can improve the characteristics of the hydrogen storage material $\mathrm{MgH}_{2}$. It also showed that the composition of the catalyst affects the particle size of the sample, even though the time and milling treatment are the same. It appears that the particle size affects the characteristics of $\mathrm{MgH}_{2}$ as a hydrogen storage material. However, there is no visible trend or in other words it cannot be directly related because there are other factors that influence such as sample homogeneity, agglomeration and the appearance of impurity phases. The appearance of these three factors is influenced by the composition and type of catalyst used, in addition to the milling time and several other things.

The 10 hours milling time used in this study has succeeded in reducing the sample to nano size. The Mg-based materials which have a nanostructure will have a larger contact area for the hydrogen reaction. The diffusion distance during

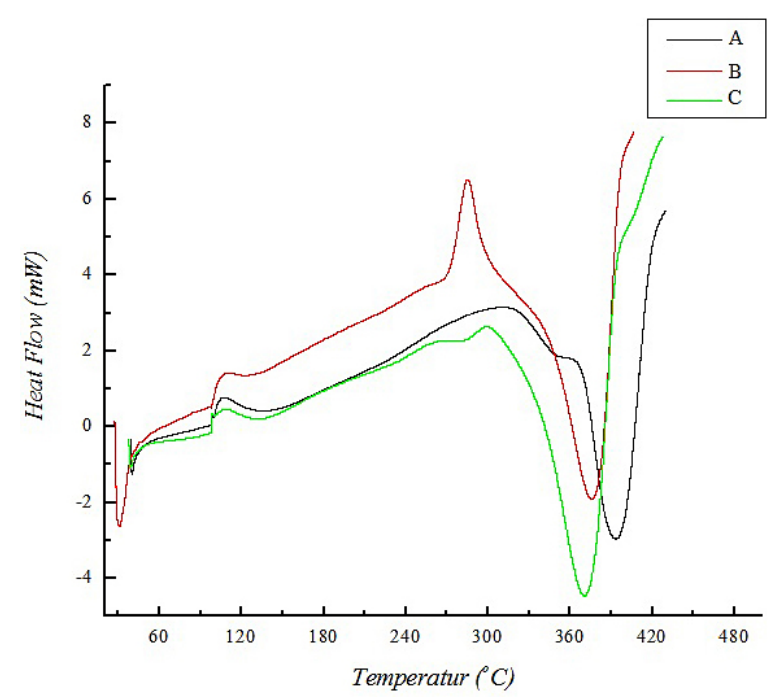

Figure 2. DSC result of the samples with different catalyst compositions

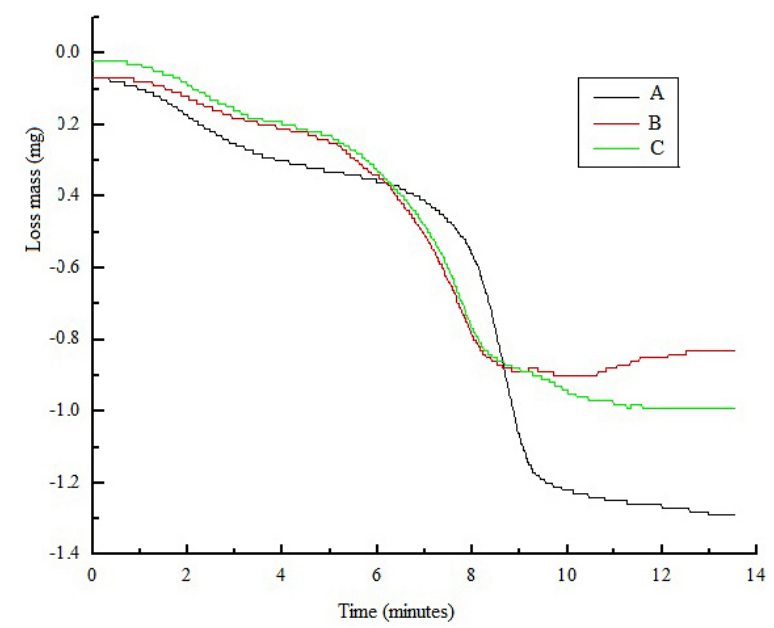

Figure 3. TGA curves of the samples with different catalyst composition

the hydrogen absorption reaction also becomes smaller so that it can increase the kinetic and thermodynamic value of $\mathrm{MgH}_{2}$ (Luo et al., 2019)

\section{CONCLUSIONS}

The obtained results showed that the natural silica extracted from rice husk ash can be used as a catalyst in hydrogen storage material $\mathrm{MgH}_{2}$. Its use with nickel has shown improved hydrogen storage characteristics such as temperature and desorption time. Sample B with a composition of $\mathrm{MgH}_{2}+5 \mathrm{wt} \% \mathrm{SiO}_{2}+10 \mathrm{wt} \% \mathrm{Ni}$ has the lowest desorption temperature, but the highest desorption time among the three samples. In turn, sample A with a composition of $\mathrm{MgH}_{2}+10 \mathrm{wt} \%$ 


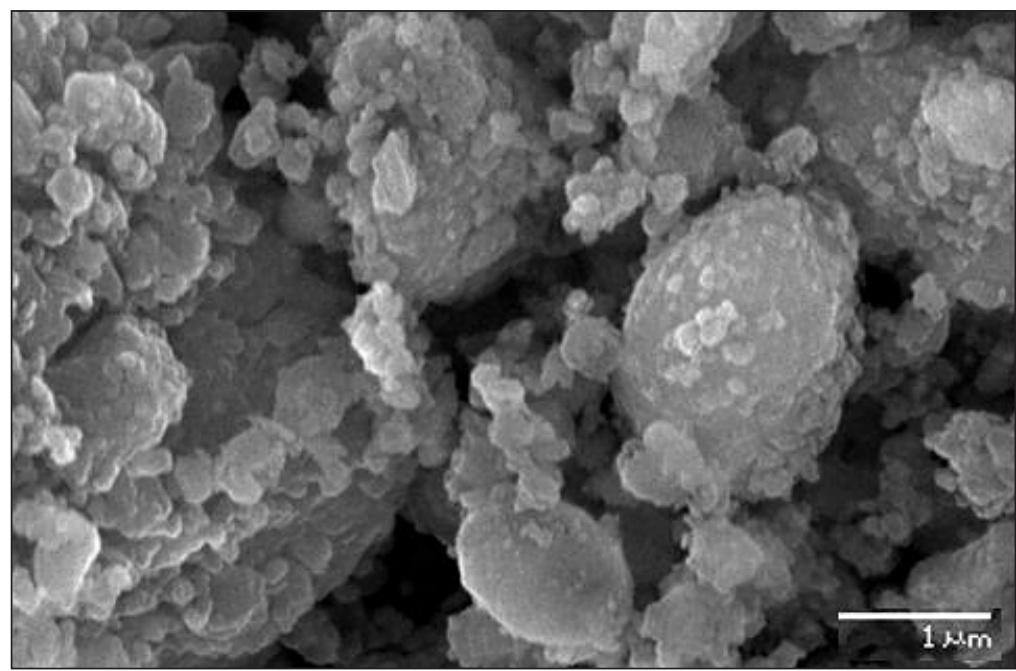

Figure 4. SEM Image of $\mathrm{MgH}_{2}+10 \mathrm{wt} \% \mathrm{SiO}_{2}+10 \mathrm{wt} \% \mathrm{Ni}$

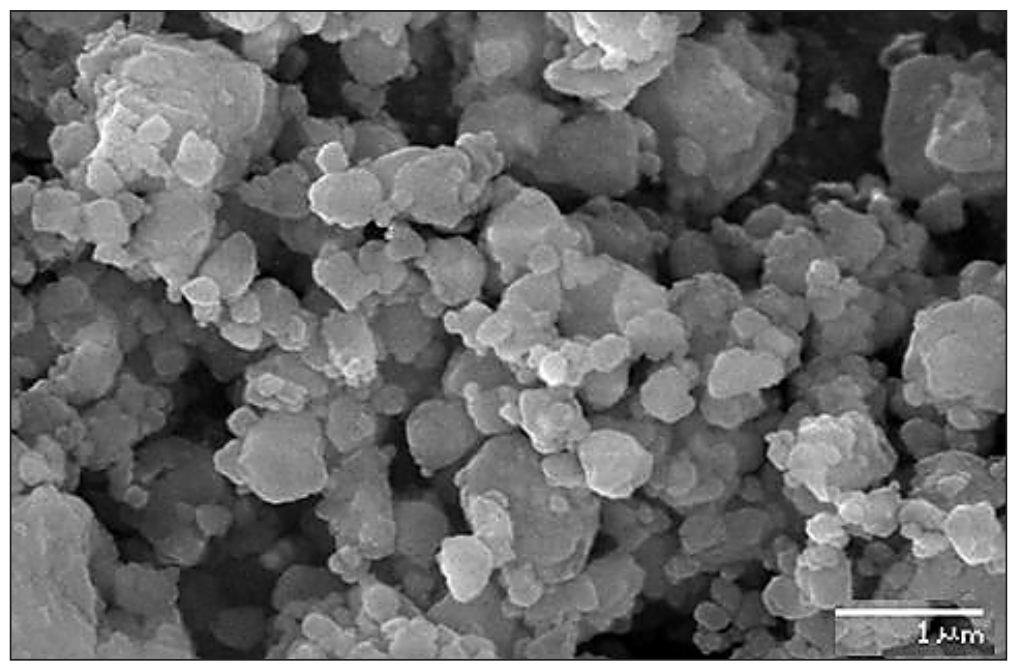

Figure 5. SEM Image of $\mathrm{MgH} 2+5 \mathrm{wt} \% \mathrm{SiO} 2+10 \mathrm{wt} \% \mathrm{Ni}$

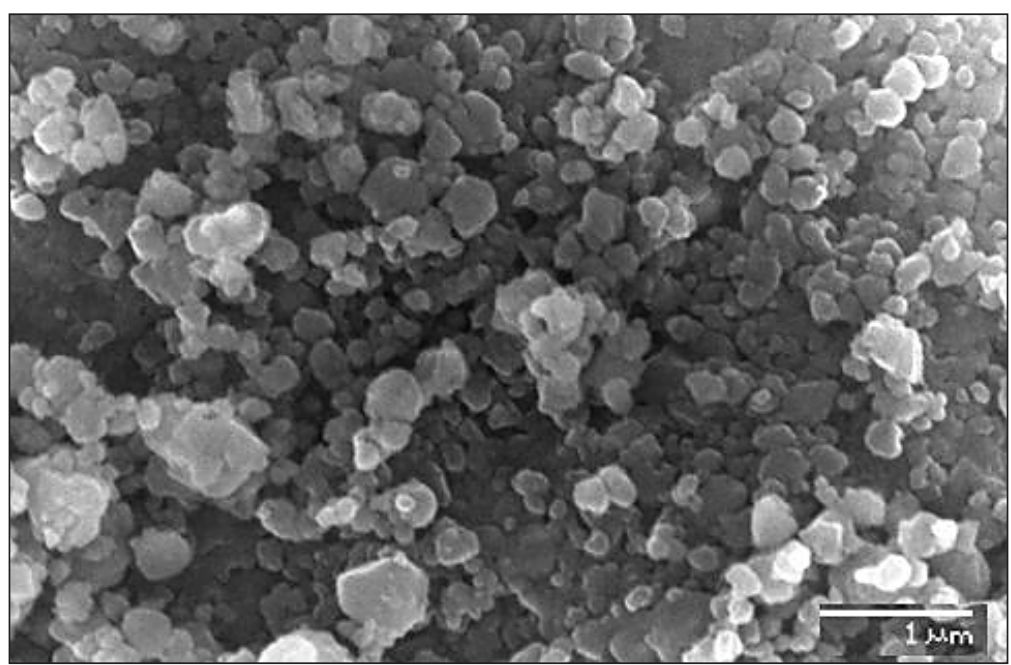

Figure 6. SEM Image of $\mathrm{MgH} 2+10 \mathrm{wt} \% \mathrm{SiO} 2+5 \mathrm{wt} \% \mathrm{Ni}$ 
$\mathrm{SiO}_{2}+10 \mathrm{wt} \% \mathrm{Ni}$ has the highest desorption temperature, but desorption time is the lowest among the three samples. For better results, further exploration of the catalyst composition and milling time is required.

\section{Acknowledgements}

Authors would like to thank Syarifah Fathmiyah, S.Si (Materials Physics Lab, Syiah Kuala University) for the assistance in sample preparation and XRD testing. The authors also gratefully acknowledge the support of the Kementrian Pendidikan, Kebudayaan, Riset dan Teknologi (Kemendikbudristek) through PKKM Research Grant Year of 2021.

\section{REFERENCES}

1. Berlouis L.E.A., Cabrera E., Hall-Barientos E., Hall P.J., Dodd S.B., Morris S., Imam M.A. 2001. Thermal analysis investigation of hydriding properties of nanocrystalline $\mathrm{Mg}-\mathrm{Ni}$ - and $\mathrm{Mg}-\mathrm{Fe}-$ based alloys prepared by high-energy ball milling. Journal of Materials Research, 16(1), 45-57. https://doi. org/10.1557/jmr.2001.0012

2. Chen M., Xiao X., Zhang M., Liu M., Huang X., Zheng J., Zhang Y., Jiang L., Chen L. 2019. Excellent synergistic catalytic mechanism of in-situ formed nanosized $\mathrm{Mg} 2 \mathrm{Ni}$ and multiple valence titanium for improved hydrogen desorption properties of magnesium hydride. International Journal of Hydrogen Energy, 44(3), 1750-1759. https://doi. org/10.1016/j.ijhydene.2018.11.118

3. Hong S.H., Song M.Y. 2018. Hydrogen absorption and release properties of $\mathrm{MgH} 2, \mathrm{Mg} 2 \mathrm{Ni}$, and $\mathrm{Ni}$-added $\mathrm{Mg}$ via reactive mechanical grinding. Journal of Korean Institute of Metals and Materials, 56(2), 155-162. https://doi.org/10.3365/ KJMM.2018.56.2.155

4. Hou X., Hu R., Zhang T., Kou H., Li J. 2013. Hydrogenation behavior of high-energy ball milled amorphous $\mathrm{Mg} 2 \mathrm{Ni}$ catalyzed by multi-walled carbon nanotubes. International Journal of Hydrogen Energy, 38(36), 16168-16176. https://doi. org/10.1016/j.ijhydene.2013.09.053

5. Jalil Z., Rahwanto A., Handoko E., Mustanir. 2017. The role of nano-Ni catalyst in $\mathrm{MgH} 2$ obtained by reactive mechanical milling method for solid hydrogen storage application. AIP Conference Proceedings, 1826. https://doi.org/10.1063/1.4979218

6. Jalil Z., Rahwanto A., Malahayati M., Mursal M., Handoko E., Akhyar H. 2018. Hydrogen storage properties of mechanical milled $\mathrm{MgH}$-nano Ni for solid hydrogen storage material. IOP Conference Series: Materials Science and Engineering, 432(1). https://doi.org/10.1088/1757-899X/432/1/012034

7. Jalil Z., Rahwanto A., Sofyan H., Usman M., Handoko E. 2018. The use of Silica from beach sand as catalyst in magnesium based hydrides for hydrogen storage materials. IOP Conference Series: Earth and Environmental Science, 105(1). https:// doi.org/10.1088/1755-1315/105/1/012093

8. Khan D., Zou J., Zeng X., Ding W. 2018. Hydrogen storage properties of nanocrystalline $\mathrm{Mg} 2 \mathrm{Ni}$ prepared from compressed $2 \mathrm{MgH} 2-\mathrm{Ni}$ powder. International Journal of Hydrogen Energy, 43(49), 22391-22400. https://doi.org/10.1016/j. ijhydene.2018.10.055

9. Khodaparast V., Rajabi M. 2015. Hydrogen Desorption Properties of MgH2-5 wt\% Ti-Mn-Cr Composite via Combined Melt Spinning and Mechanical Alloying. Procedia Materials Science, 11, 611-615. https://doi.org/10.1016/j.mspro.2015.11.092

10. Kou H., Hou X., Zhang T., Hu R., Li J., Xue X. 2013. On the amorphization behavior and hydrogenation performance of high-energy ball-milled $\mathrm{Mg} 2 \mathrm{Ni}$ alloys. Materials Characterization, 80, 21-27. https:// doi.org/10.1016/j.matchar.2013.03.009

11. Kwak Y.J., Lee S.H., Mumm D.R., Song M.Y. 2015. Development of a Mg-based hydrogen-storage material by addition of $\mathrm{Ni}$ and $\mathrm{NbF} 5$ via milling under hydrogen. International Journal of Hydrogen Energy, 40(35), 11908-11916. https://doi.org/10.1016/j. ijhydene.2015.04.111

12. Li J., Li B., Shao H., Li W., Lin H. 2018. Catalysis and downsizing in $\mathrm{Mg}$-based hydrogen storage materials. Catalysts, 8(2). https://doi.org/10.3390/ catal 8020089

13. Luo Q., Li J., Li B., Liu B., Shao H., Li Q. 2019. Kinetics in Mg-based hydrogen storage materials: Enhancement and mechanism. Journal of Magnesium and Alloys, 7(1), 58-71. https://doi.org/10.1016/j. jma.2018.12.001

14. Malahayati, Ismail, Mursal, Jalil Z. 2018. The use of silicon oxide extracted from rice husk ash as catalyst in magnesium hydrides $(\mathrm{MgH} 2)$ prepared by mechanical alloying method. Journal of Physics: Conference Series, 1120(1). https://doi.org/10.108 8/1742-6596/1120/1/012061

15. Malahayati M., Yufita E., Ismail I., Mursal M., Idroes R., Jalil Z. 2021. Hydrogen Desorption Properties of $\mathrm{MgH} 2+10 \mathrm{wt} \% \mathrm{SiO} 2+5 \mathrm{wt} \%$ Ni Prepared by Planetary Ball Milling. Bulletin of Chemical Reaction Engineering \& Catalysis, 16(2), 280-285. https:// doi.org/10.9767/bcrec.16.2.10220.280-285

16. Malahayati, Nurmalita, Ismail, Machmud M.N., Jalil Z. 2021. Sorption behavior of MgH2-Ti for Hydrogen storage material prepared by high pressure milling. Journal of Physics: Conference Series, 
1882(1), 012005. https://doi.org/10.1088/1742-659 6/1882/1/012005

17. Mustanir M., Jalil Z. 2009. Hydrogen Sorption Behavior of the MgH2-Ni Prepared by Reactive Mechanical Alloying. IPTEK The Journal for Technology and Science, 20(4). https://doi.org/10.12962/ j20882033.v20i4.19

18. Patternson A.L. 1939. Scherrer Formula. Physical review, 56, 978.

19. Rahwanto A., Ismail I., Nurmalita N., Mustanir, Jalil Z. 2021. Nanoscale Ni as a catalyst in MgH2 for hydrogen storage material. Journal of Physics: Conference Series, 1882(1), 012010. https://doi.or g/10.1088/1742-6596/1882/1/012010

20. Rahwanto A., Jalil Z., Akhyar, Handoko E. 2020. Desorption properties of mechanically milled $\mathrm{MgH} 2$ with double catalysts $\mathrm{Ni}$ and $\mathrm{SiC}$. IOP Conference Series: Materials Science and Engineering, 931(1). https://doi.org/10.1088/1757-899X/931/1/012012

21. Rajabpour F., Raygan S., Abdizadeh H. 2016. The synergistic effect of catalysts on hydrogen desorption properties of $\mathrm{MgH} 2-\mathrm{TiO} 2-\mathrm{NiO}$ nanocomposite. Materials for Renewable and Sustainable Energy, 5(4), 1-9. https://doi.org/10.1007/ s40243-016-0084-y

22. Ranjbar A., Guo Z.P., Yu X.B., Attard D., Calka A., Liu H.K. 2009. Effects of SiC nanoparticles with and without $\mathrm{Ni}$ on the hydrogen storage properties of $\mathrm{MgH} 2$. International Journal of Hydrogen Energy, 34(17), 7263-7268. https://doi.org/10.1016/j. ijhydene.2009.07.005

23. Sadhasivam T., Kim H.T., Jung S., Roh S.H., Park J.H., Jung H.Y. 2017. Dimensional effects of nanostructured $\mathrm{Mg} / \mathrm{MgH} 2$ for hydrogen storage applications: A review. Renewable and Sustainable Energy Reviews, 72, 523-534. https://doi.org/10.1016/j. rser.2017.01.107

24. Sudibandriyo M., Wulan P.P.D.K., Prasodjo P. 2015. Adsorption capacity and its dynamic behavior of the hydrogen storage on carbon nanotubes. International Journal of Technology, 6(5), 1128-1136.

25. Varin R.A., Czujko T., Wronski Z. 2006. Particle size, grain size and $\gamma-\mathrm{MgH} 2$ effects on the desorption properties of nanocrystalline commercial magnesium hydride processed by controlled mechanical milling. Nanotechnology. https://doi. org/10.1088/0957-4484/17/15/041

26. Varin R.A., Czujko T., Wronski Z.S. 2009. Nanomaterials for solid state hydrogen storage. Nanomaterial for Solid State Hydrogen Storage.

27. Yartys V.A., Lototskyy M.V., Akiba E., Albert R., Antonov V.E., Ares J.R., Baricco M., Bourgeois N., Buckley C.E., Bellosta von Colbe J.M., Crivello J.C., Cuevas F., Denys R.V., Dornheim M., Felderhoff M., Grant D.M., Hauback B.C., Humphries T.D., Jacob I., Zhu M. 2019. Magnesium based materials for hydrogen based energy storage: Past, present and future. International Journal of Hydrogen Energy, 44(15), 7809-7859. https://doi.org/10.1016/j. ijhydene.2018.12.212

28. Zeng L., Qing P., Cai F., Huang X., Liu H., Lan Z., Guo J. 2020. Enhanced Hydrogen Storage Properties of $\mathrm{MgH} 2$ Using a Ni and $\mathrm{TiO} 2 \mathrm{Co}-\mathrm{Doped} \mathrm{Re}-$ duced Graphene Oxide Nanocomposite as a Catalyst. Frontiers in Chemistry, 8(March). https://doi. org/10.3389/fchem.2020.00207

29. Zhang Q., Zang L., Huang Y., Gao P., Jiao L., Yuan H., Wang Y. 2017. Improved hydrogen storage properties of $\mathrm{MgH} 2$ with Ni-based compounds. International Journal of Hydrogen Energy, 42(38), 24247-24255. https://doi.org/10.1016/j. ijhydene.2017.07.220

30. Zhang Y.H., Ablong-wen L.I., Feng D.C., Gong P.F. Shang H.W., Guo S.H. 2017. Hydrogen storage behavior of nanocrystalline and amorphous $\mathrm{La}-\mathrm{Mg}-$ Ni-based LaMg12-type alloys synthesized by mechanical milling. Transactions of Nonferrous Metals Society of China (English Edition), 27(3), 551-561. https://doi.org/10.1016/S1003-6326(17)60061-X 